\title{
Géo 370 : dossier Nouvelle-Calédonie
}

Isabelle Leblic

\section{(2) OpenEdition}

Journals

Édition électronique

URL : http://journals.openedition.org/jso/6168

DOI : 10.4000/jso.6168

ISSN : $1760-7256$

Éditeur

Société des océanistes

Édition imprimée

Date de publication : 15 décembre 2010

Pagination : 271

ISBN : 978-2-85430-027-7

ISSN : 0300-953x

Référence électronique

Isabelle Leblic, «Géo 370 : dossier Nouvelle-Calédonie », Journal de la Société des Océanistes [En ligne] 130-131 | 2010, mis en ligne le 15 décembre 2010, consulté le 24 septembre 2020. URL : http:// journals.openedition.org/jso/6168; DOI : https://doi.org/10.4000/jso.6168

(c) Tous droits réservés 
Il s'agit plutôt d'une récitation de nom de clans et de lignages et de leurs alliances et parcours.

Ces chants de toutes sortes sont un autre moyen de la tradition orale kanak pour conserver et transmettre ce qui marque la vie quotidienne. Tristes ou joyeux, ils sont l'empreinte de l'histoire et de la vie, mais aussi parfois l'expression de l'espoir d'un monde meilleur.

Isabelle LEBLIC, CNRS-LACITO, Villejuif

Géo 370 : dossier Nouvelle-Calédonie, décembre 2009, pp. $46-107$.

Le magazine Géo a publié en décembre dernier un dossier spécial de 60 pages sur la Nouvelle-Calédonie. Une interview de Christian Karembeu, célèbre footballeur français originaire des îles Loyauté, introduit une série d'articles abordant d'importants sujets d'actualité de la Nouvelle-Calédonie : la protection du lagon d'Ouvéa inscrit en 2008 au patrimoine mondial de l'UNESCO (pp. 54-59) avec un très court texte commentant de belles photos de cette île réputée « la plus proche du paradis », une carte présentant les six zones de l'archipel inscrites à ce même patrimoine avec leurs espèces remarquables (pp. 60-61), « les avancées chaotiques du destin commun » (pp. 70-79), « des squats dans la ville » (pp. 80-82), « Nickel, le bon filon enfin partagé » (pp. 84-88), « ainsi parlent les ancêtres » (p. 90), un encart dépliant sur une collection privée d'art kanak accompagnant un article sur le collectionneur William Costes (p. 97), « des artistes qui assurent la relève » (pp. 98-100), pour terminer par la présentation d'un sentier de randonnée entre eau et forêt dans le sud de la Grande Terre (pp. 102-104) et quelques conseils avant de partir (p. 106).

Très grand public, ce dossier peut constituer une introduction à la Nouvelle-Calédonie d'aujourd'hui mais laisse sur sa faim tout connaisseur du pays. De même, les orientations bibliographiques données sont des plus limitées. À lire pour le plaisir des belles photos plus que pour le contenu des textes.

Isabelle LEBLIC, CNRS-LACITO, Villejuif

Di Piazza Anne and Erik Pearthree (eds), 2008. Canoes of the Grand Ocean, Oxford, Archaeopress, BAR International Series 1802, vI-154 p., bibliogr., cartes, nombreuses ill. dans le texte.

En présentant cette réunion de huit contributions d'archéologie maritime, A. Di Piazza souligne d'emblée ce qu'a de plaisant et de fascinant le vieux terme français de « Grand Océan » choisi pour intituler ce volume. Dans toute fascination entre forcément une part d'appréhension, qu'on songe à celle des anciens navigateurs défiant les vastitudes et les colères du Pacifique ou à celle des scientifiques d'aujourd'hui qui tentent de reconstituer leur histoire, sujet immense et d'une importance essentielle pour la compréhension du peuplement de l'Océanie. Sur ce thème réellement fascinant et avec l'aspect plaisant que lui donnent ses nombreuses illustrations, cet ouvrage ajoute à cette part nécessaire d'appréhension une autre des plus évitables et superflues, avec sa fragile couverture à « dos collé » qui laisse vite échapper son contenu en feuilles volantes et finit par rendre sa lecture hasardeuse. Les bibliothèques devront le faire relier avant de le mettre à la disposition du public, sous les alizés comme sous d'autres vents.

Les contributions sont réparties en trois sections (un peu abusivement dénommées « sessions » comme s'il s'agissait d'un colloque) à dominante respectivement historique, technique et spéculative, non sans incursions nécessaires des auteurs d'un domaine à l'autre, l'architecture navale venant ainsi fournir des arguments aux historiens, comme on va le voir. L'ambition de la première partie, «Navigators as the principal actors in cross-cultural encounters », est d'éclairer par leur contexte historique les témoignages des premiers Européens à avoir décrit les navigateurs traditionnels du «Grand Océan». Anne Salmond («Voyaging exchanges: Tahitian Pilots and European Navigators », pp. 23-46) revient notamment sur la « carte de Tupa'ia » dressée par Cook sur les indications du pilote tahitien, mais elle en compare aussi les données avec ce que retirèrent des connaissances des insulaires les deux vaisseaux de guerre espagnols de passage en 1774, pour dresser en conclusion une liste d'îles remarquable de précision. Spécialiste chevronné de l'auteur de l'Essai sur la construction navale des peuples extraeuropéens... (1843), Eric Rieth («Traditional Oceanic Canoes as seen by Admiral Paris », pp. 47-68) montre sur quel travail d'observation directe, mais aussi de documentation historique repose cette œuvre classique. Par contraste avec les représentations européennes, Richard Feinberg poursuit son analyse des conceptions traditionnelles des insulaires d'Anuta, et les examine ici dans leurs implications maritimes (« Polynesian Representations of Geographical and Cosmological Space: Anuta, Solomon Islands », pp. 69-84).

Due à Carlos Mondragón et Miquel Luque Talaván, la contribution ouvrant cette première partie («Early European Descriptions of Oceanic Watercraft. Iberian Sources and Contexts », pp. 9-22) est peut-être la plus ambitieuse et la plus sujette à discussion. Elle revient sur deux escales des navigateurs espagnols commandés successivement par Mendaña et Quirós, la première au sud-ouest de Santa Isabel en février 1568, la deuxième à Taumako en avril 1606. Dans le premier cas, les insulaires de Furona étant venus proposer un porc aux Espagnols en échange d'un canot que ces derniers leur avaient pris, les auteurs de l'article n'ont pas de mal à en inférer que les insulaires ne prenaient pas les Blancs pour des fantômes ou des esprits. Dans le deuxième cas que les auteurs examinent plus longuement (pp. 13-20), les Espagnols restèrent à terre une dizaine de jours et rapportèrent des descriptions admiratives des embarcations des insulaires. Or ces témoignages ne correspondraient pas au célèbre te puke propre à Taumako, où cherche à le remettre en usage l'association « Vaka 